\title{
Reproductive performance and nest-site selection of White-naped Cranes Grus vipio in the Ulz river valley, north-eastern Mongolia
}

\author{
UTE BRADTER, SUNDEV GOMBOBAATAR, CHULUUNBAATAR \\ UUGANBAYAR, TRACY E. GRAZIA and KLAUS-MICHAEL EXO
}

\section{Summary}

North-eastern Mongolia is an important breeding area for the globally threatened White-naped Crane Grus vipio. We studied reproductive performance and the influence of factors related to livestock grazing on reproduction and nest-site selection of the White-naped Crane population in the Ulz river valley, north-eastern Mongolia in 2000 and 2001. In 2001, 42 territorial pairs were found in $270 \mathrm{~km}$ of river basin. Recruitment was $18-22 \%$ resulting in $0.5-0.6$ juveniles per territorial pair. The years 2000 and 2001 were within a dry period and recruitment might have been below the long-term average. White-naped Crane nests were significantly associated with river basin sections containing shallow water-bodies. The number and extent of shallow water-bodies are likely to be a limiting factor for breeding population size. Nest-sites in waterbodies were selected for high nest concealment, but nests were initiated even when concealing vegetation was not available. Only $26 \%$ of nests were $>90 \%$ concealed suggesting that appropriate cover was often not available. Nest-sites were also selected for low grazing intensity. No correlation was found between hatching or fledging success and nest concealment or grazing intensity. Brood-size of successful pairs was higher if the home range was ungrazed, but further investigations are needed to clarify whether this was caused by absence of livestock grazing or other factors. Both because of internationally important numbers and because of a potentially high reproductive output, the study area is of high importance for the species.

\section{Introduction}

The world population of the globally threatened White-naped Crane Grus vipio is estimated to be 5,500-6,500 individuals (BirdLife International 2000). The species breeds in north-eastern China, north-eastern Mongolia and adjacent areas of southeastern Russia (Meine and Archibald 1996, BirdLife International 2001). In Mongolia, breeding pairs were not discovered until the late 1960s (Bold et al. 1995). Since this discovery, north-eastern Mongolia has been identified as an important breeding area for the species, with the Onon and Ulz river basins and their tributaries being the most important (Goroshko and Tseveenmyadag 2001, 2002, Gombobaatar 2002a, b). Nevertheless, little information is available on the biology and ecology of the species, such as habitat selection, reproductive success, and factors influencing reproduction (Gombobaatar and Sumiya 1998, Tseveenmyadag and Goroshko 2001, Goroshko and Tseveenmyadag 2001, 2002, Gombobaatar 2002a, b, Goroshko 2002). 
The main income for families in the Mongolian countryside is nomadic pastoralism. Overgrazing has become a serious problem in some areas due to a considerable increase in livestock numbers and a change from a nomadic to a more sedentary lifestyle (Kerr and Treskonova 1995, Oyun-Erdene 1998). Livestock grazing may have a negative impact on White-naped Cranes by degrading breeding habitat and disturbing breeding birds. Other human activities that may affect White-naped Crane breeding areas include mining, haymaking, and an increased frequency of steppe fires. Presently north-eastern Mongolia is relatively unspoiled by development activities. This could change rapidly because the Mongolian government has plans for largescale agricultural development, as well as industrial and infrastructural projects (BirdLife International 2003). These plans are potentially detrimental to not only the White-naped Crane population and their habitat, but also to other threatened species such as the globally endangered Swan Goose Anser cygnoides (BirdLife International 2000) that share the same wetland habitat (BirdLife International 2003).

The aims of this study were:

(I) to obtain data on breeding pair numbers and reproductive success of Whitenaped Cranes in order to more comprehensively assess the importance of the Mongolian breeding areas for the species;

(2) to determine whether present human activities influence reproduction of the species, especially whether factors related to livestock grazing influence nest-site selection or breeding success.

\section{Study area and methods}

The study area was situated in north-eastern Mongolia (Figure 1) covering $270 \mathrm{~km}$ of the Ulz river basin between $48^{\circ} 51^{\prime} \mathrm{N} 112^{\circ} 7^{\prime} \mathrm{E}$ in Khentii aimag (province) and $49^{\circ} 42^{\prime} \mathrm{N}$ $115^{\circ} 19^{\prime} \mathrm{E}$ in Dornod aimag and the nearby lake Galuut Nuur. The river basin is c. $300 \mathrm{~m}$ to c. $3 \mathrm{~km}$ broad. Elevation varies between $640 \mathrm{~m}$ (east) and 1,000 $\mathrm{m}$ (west). Most of the river basin is open with only a few willow Salix sp. trees. Shallow waterbodies (both seasonally and permanently flooded areas and ponds) occur irregularly throughout the river basin. The vegetation consists largely of Cyperaceae, Juncaceae and reed Phragmites australis syn communis. The Ulz river basin is listed as a key breeding area for White-naped Cranes (Meine and Archibald 1996). The study area covered part B of Mongol Daguur Strictly Protected Area and parts of Ugtam Nature Reserve. Mongol Daguur Strictly Protected Area is also a Ramsar site, North East Asian Crane Network site, and part of the trilateral Dauria International Reserve of China, Russia and Mongolia (North East Asian Crane Site Network Newsletter 1998). Livestock herding families live along most parts of the river basin. Two villages, Bayan-Uul $\left(49^{\circ} 7^{\prime} \mathrm{N} 112^{\circ} 41^{\prime} \mathrm{E}\right)$ and Dashbalbar $\left(49^{\circ} 33^{\prime} \mathrm{N} 114^{\circ} 24^{\prime} \mathrm{E}\right)$ are situated within the study area. In 2000, the eastern $80 \mathrm{~km}$ of the study area including Galuut Nuur (SA I) were studied. In 2001, the whole study area was surveyed. However, for the westernmost $15 \mathrm{~km}$ of the study area, we cannot exclude the possibility of a failed first breeding attempt prior to our arrival for some pairs. Therefore, only the number of pairs, recruitment, and nest-site selection data were recorded in this area. The Ulz river basin experiences large fluctuations in wetland condition and extent between wet and dry periods (Goroshko and Tseveenmyadag 2002). The years 2000 and 2001 fell within a dry period (Goroshko and Tseveenmyadag 2002). SA I experienced the strongest drought conditions of the study area in both years. Temperature and precipitation 


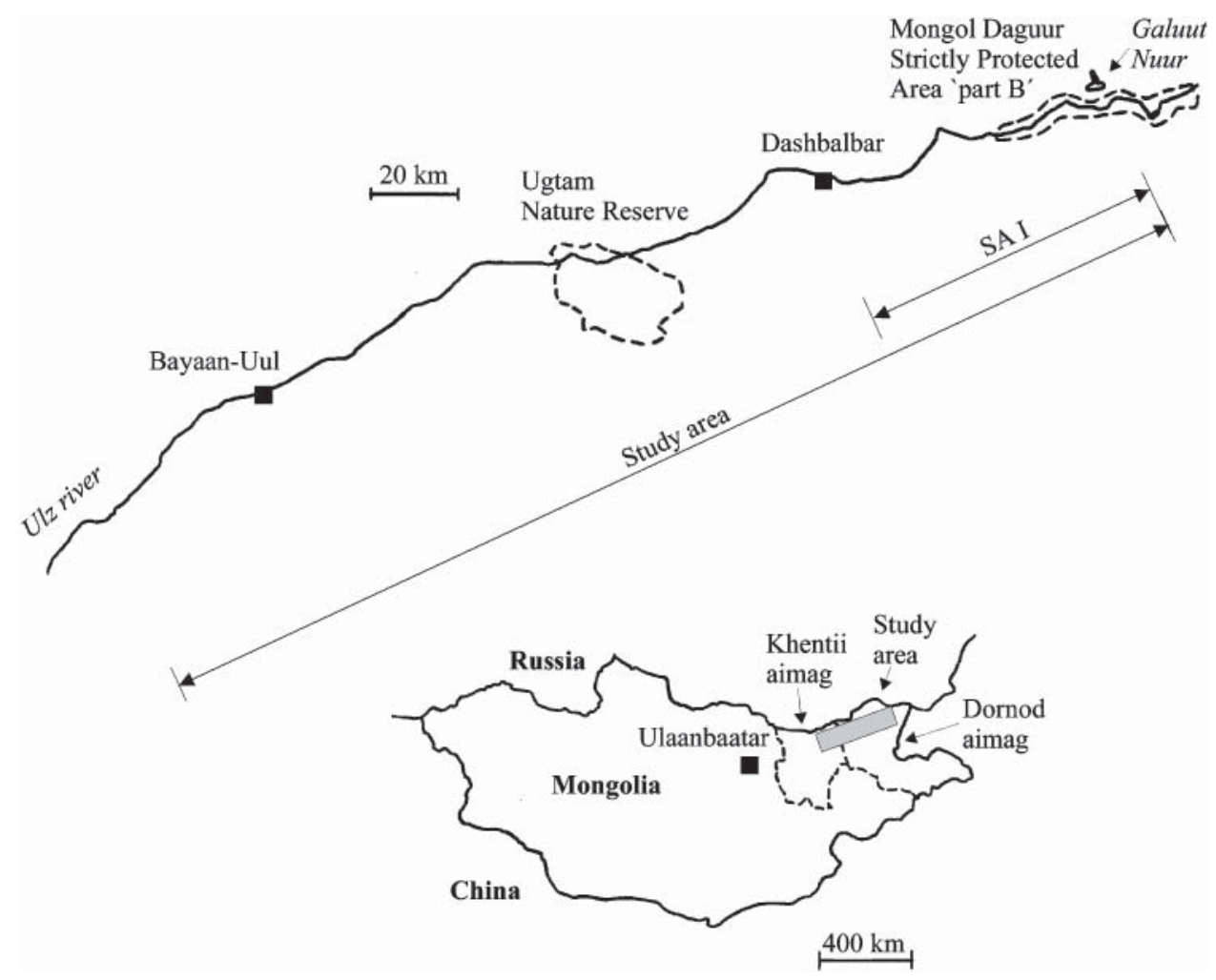

Figure 1. The study area at the Ulz river and its location in north-eastern Mongolia. Broken lines show protected areas. A survey was carried out in SA I in 2000 and in the whole study area in 2001.

data were obtained from the weather stations in Bayan-Uul and Dashbalbar. In 2000, a steppe fire had burned large areas in the eastern part of SA I prior to our investigations. In 2001, a steppe fire burned areas west of Bayan-Uul in the middle of May. Fieldwork was carried out from II May to 31 August 2000 and from 7 May to 20 August 2001.

\section{Reproductive performance and nest-site characteristics}

In both years, the study area was surveyed once in May with telescopes and binoculars from observation points on hills along the river basin to determine the number of territorial pairs. Observation points were $3-5 \mathrm{~km}$ apart and usually allowed full cover of the whole river basin including the proximate side of the river basin surveyed by the adjacent points and any cranes recorded there. Due to the openness of the landscape, bias of counting the same pair twice can be ruled out but with one exception; no hills were available and the river basin was not entirely visible in approximately $3 \mathrm{~km}$ of the Mongol Daguur Strictly Protected Area. Observations here were complimented by unison call surveys at dawn. GPS locations were taken to specify the location of all territorial pairs or single cranes. 
Pairs were classified as territorial when either incubation or nest-building attempts were observed or when, after a minimum of 10 days, the pair was recorded again in the same location (see Bibby et al. 1992). Pairs were classified as non-breeding when no egg-laying was recorded regardless of whether or not the building of start nest(s) had been observed. The first non-breeding pairs from the eastern dry areas had already left their territories in late May; therefore surveys were not conducted after May. Pairs newly appearing from that time onward and showing territorial behaviour were not counted as territorial pairs (as these pairs might have abandoned another territory held earlier). These pairs along with non-territorial pairs, single cranes, a group of three and a group of eight recorded during the study are not taken into consideration in this article.

Breeding status of pairs was determined by observation. Where possible, nests were located and visited under favourable weather conditions before late afternoon, but otherwise, nests were visited several days later. On 10 delayed nest visits, eggs had already hatched or been predated. Nest visits were limited to a maximum of 10 minutes. Hatching dates of eggs were estimated by a flotation test based on data from Florida Sandhill Cranes Grus canadensis pratensis (Fisher and Swengel 1991). Nest location (from GPS), the number of eggs, egg length and width (to o.I mm), nest diameter and water depth (to the nearest centimetre) averaged over four samples around the nest were measured. In 2001, vegetation height and water depth averaged over four samples at $1.5 \mathrm{~m}$ distance from the nest, grazing intensity at the nest and nest concealment were recorded additionally. Nest concealment was estimated as the percentage of a $360^{\circ}$ circle around the nest where vegetation would hide an incubating crane from potential ground predators. Grazing intensity was estimated in four categories (none, little, middle, high) and additionally estimated for the area enclosed by all sightings of a territorial pair (hereafter referred to as the home range). The presence of grazing at nest-sites and of grazing in the home range was compared by chi-square test (Sokal and Rohlf 1995). Six nests (including one re-nest) were visited in 2000 and 28 nests (including four re-nests) in 2001.

Loss of clutches or chicks, possible replacement clutches and fledging success were recorded through subsequent observations of all pairs until August. When no chicks were seen with the parent birds after incubation was terminated, nests were revisited and searched for eggshell fragments. These were used to determine whether eggs had hatched or were depredated (Sargent et al. 1998). Hatching was counted as successful when at least one chick was recorded as hatched. For some pairs, failure could not be dated to before or after hatching (hatching not confirmed). Water depth at nest-sites, nest concealment, grazing intensity at the nest, and grazing intensity in the home range were compared between nests with confirmed and unconfirmed hatching and were compared between pairs with successful and unsuccessful raising of at least one 4-week-old chick by Mann-Whitney $U$-test (Sokal and Rohlf 1995). Recruitment is calculated as the number of juveniles as a percentage of the total number of territorial adults and their chicks. Fledging success is calculated as the percentage of breeding pairs (BP) that fledged at least one chick. Recruitment and fledging success are given as minimum - maximum figures. Minimum figures represent fledged chicks and chicks close to fledging ( $\geq 8$ weeks, 2 in 2001) at the end of the field season. White-naped Cranes fledge at about 70-75 days (Iičev and Flint 1989, Meine and Archibald 1996). Maximum figures represent all chicks alive at the end of the study, thus including chicks $\geq_{4}$ weeks (mostly from re-nests). 


\section{Distribution of White-naped Cranes within the river basin}

In 2000, we recorded vegetation type (reed, wet meadow, reed + wet meadow), occurrence of fire in the previous winter or spring, and ground condition (height of standing water, ground moist or dry) in the eastern $50 \mathrm{~km}$ of the study area. Two transects routes were identified, one either side of the river, about equidistant between the river and the outer limit of the river basin. The above measurements were taken at set points every kilometre along the transect routes. Small water-bodies between sampling points and the wetland area on the south-eastern side of Galuut Nuur were additionally sampled. In total, 145 points were sampled between II and 24 June 2000. Based on these data, a habitat map was produced. Observations of cranes and recordings of nests during the study in 2000 were plotted on the map. On the Galuut Nuur wetland and on each side of the river, the map was then divided into wetland sections $3 \mathrm{~km}$ long. For each of the resulting 35 sections vegetation type, ground condition (dry or with a water-body), whether recently burned or not, presence or lack of a nest and observation or lack of observation of White-naped Cranes were analysed. In two cases, about half the section was burned and the condition in which White-naped Crane observations were recorded was taken as the relevant (burned in one case, unburned in the other). Chi-square tests were carried out for each habitat characteristic (vegetation type, presence of water-body, recent burn) with White-naped Crane observation or nest presence (Sokal and Rohlf 1995).

\section{Nest-site selection}

In 2000, habitat characteristics of nest areas were compared with habitat characteristics of random areas. Random areas had to be in the river basin and a minimum of $1 \mathrm{~km}$ from any territorial White-naped Crane observation. Data were recorded at 29 points per nest and per random area. Samples were taken at the nest-site and the random point and at $10 \mathrm{~m}, 20 \mathrm{~m}, 30 \mathrm{~m}, 40 \mathrm{~m}, 50 \mathrm{~m}, 75 \mathrm{~m}$ and $100 \mathrm{~m}$ distance in the four cardinal directions. At each point, water depth, vegetation height (averaged over three samples), vegetation density (0, 25\%, 50\%, 75\%, 100\% of ground covered), dominating vegetation type (steppe, wet meadow, reed) and number of plant species in a $50 \times 50 \mathrm{~cm}$ square were recorded. Sampling took place from 21 to 26 August to avoid prolonged disturbance during incubation or the early chick-rearing period. Five nest-sites and six random sites in the eastern $50 \mathrm{~km}$ of the study area were sampled. The distance of six nests sites to the nearest family home was measured. Water depth of sampled points (in the categories dry, moist, I-1O cm, II $-40 \mathrm{~cm},>40 \mathrm{~cm}$ ), vegetation density, vegetation type and number of plant species of sampled points (in the categories one, 2-5, 6-15) were compared between nest areas and random areas by chi-square tests.

In 2001, habitat characteristics at nest-sites were compared with habitat characteristics at points in the nesting area resembling general features of the nest-site. For example, when the nest was positioned on the south side of a water-body, a random point on the south side of another water-body in the same nesting area was selected. If no other water-body was present in the nesting area, a random point on the same water-body was taken. As nesting area, we defined the wetland area within approximately $600 \mathrm{~m}$ of the nest-site that was not used by a neighbouring territorial pair. Habitat characteristics (water and vegetation height, concealment, grazing intensity: 
see above) were recorded at nest-sites in the whole study area during the first nest visit and at corresponding random points on the same day. Concealment, water depth and vegetation height between nest-sites and corresponding random points were compared by Wilcoxon tests. Grazing intensity between nest-sites and corresponding random points, as well as between nest-sites and the home range, was compared by sign tests (Sokal and Rohlf 1995).

\section{Results}

\section{Reproductive performance}

In 2000, 17 territorial pairs were recorded in SA I (Table 1 ). In the entire study area in 2001, one pair was recorded on Galuut Nuur and 41 pairs in the Ulz river valley, resulting in a theoretical density of 1.5 pairs per $10 \mathrm{~km}$ of river basin (had pairs been distributed evenly). Highest concentrations were 11 pairs in $c .22 \mathrm{~km}^{2}$ (western part of Mongol Daguur Strictly Protected Area and adjacent areas), five pairs in $c .6 \mathrm{~km}^{2}$ (west end of study area) and five pairs in $c$. II $\mathrm{km}^{2}$ of river basin (west of Bayan-Uul). Nearest distance between nests was $177 \mathrm{~m}$ in a wetland area inhabited by two pairs.

In $2001,86 \%$ of pairs (3I BP) produced a clutch. All the non-breeding pairs occurred in eastern areas (SA I). In 2000 in SA I, only $41 \%$ of pairs (7 BP) attempted to breed. Outside the swampy western $c .8 \mathrm{~km}$ of Mongol Daguur Strictly Protected Area, SA I was very dry both in 2000 and 2001 and the amount and extent of water-bodies was reduced compared with 1999 (pers. obs.).

Mean clutch size was 1.9 eggs $(n=24$, Table 2$)$. Brood-size of successful pairs was similar in the two years (1.3-1.4 juveniles per BP) (Table 1). In 2001 about half of BP were successful $(45-52 \%, n=31)$ and recruitment in the whole study area was $18-22 \%$.

Of 23 nest failures in both years, 13 can be dated. Four occurred during incubation and nine during chick-rearing. Among datable chick losses, none was recorded for a

Table 1. Number of territorial pairs (TP), number and percentage of breeding pairs (BP) and reproductive success of the White-naped Crane in the Ulz river valley and Galuut Nuur, north-eastern Mongolia in 2000 and 2001.

\begin{tabular}{|c|c|c|c|}
\hline \multirow[b]{2}{*}{ Length of study area: Year: } & \multirow{2}{*}{$\frac{\text { SAI }}{80 \mathrm{~km}, 2000}$} & \multicolumn{2}{|l|}{ Study area } \\
\hline & & $255 \mathrm{~km},{ }^{a} 2001$ & $270 \mathrm{~km}, 2001$ \\
\hline No. of TP & 17 & 36 & 42 \\
\hline No. of BP (\% of TP) & $7(41 \%)$ & $31(86 \%)$ & \\
\hline No. (\%) of BP successful at first attempt & $4(57 \%)$ & $14(45 \%)$ & \\
\hline No. of fledged juveniles from first attempt & 5 & 18 & \\
\hline No. (\%) of unsuccessful BP re-nesting & $1(33 \%)$ & $5(29 \%)$ & \\
\hline No. of juveniles from re-nests & 2 & 4 & \\
\hline Fledging success ${ }^{b}$ & $57-71 \%$ & $45-52 \%$ & \\
\hline Brood-size of $\mathrm{BP}^{b}$ & $0.7^{-1.0}$ & $0.6-0.7$ & \\
\hline Brood-size of successful $\mathrm{BP}^{b}$ & $1.3-1.4$ & $1.3-1.4$ & 1.3 \\
\hline Brood-size of $\mathrm{TP}^{b}$ & $0.3-0.4$ & $0.5-0.6$ & $0.5-0.6$ \\
\hline Recruitment $^{b}$ & $13-17 \%$ & $20-23 \%$ & $18-22 \%$ \\
\hline Median hatching date & 9 June $(n=5)$ & & 4 June $(n=10)$ \\
\hline
\end{tabular}

${ }^{a}$ Excluding western $15 \mathrm{~km}$ where a failed first breeding attempt prior to the survey is a possibility.

${ }^{b}$ Minimum figures represent fledged juveniles and juveniles close to fledging ( $\geq 8$ weeks); maximum figures represent all juveniles alive at the end of the study ( $\geq_{4}$ weeks). 
Table 2. Mean, standard deviation (SD) and sample size (n) of clutch size, egg and nest measurements from White-naped Crane nests in the Ulz river valley and Galuut Nuur in 2000 and 2001.

\begin{tabular}{lccr}
\hline & Mean & SD & $n$ \\
\hline Clutch-size & 1.9 & 0.3 & 24 \\
Egg length $(\mathrm{mm})$ & 92.4 & 4.2 & 44 \\
Egg width $(\mathrm{mm})$ & 60.6 & 2.1 & 44 \\
Nest diameter $(\mathrm{cm})$ & 95 & 25 & 33 \\
\hline
\end{tabular}

chick older than 1 month. In most cases, no evidence for the causes of nest failure was found. One nest on a river island was flooded during incubation. Two nests were found in great disarray suggesting a mammalian predator. However, on one of these, remains of a hatched egg and a predated egg were found. No egg or chick loss directly caused by steppe fires was recorded, but one nest in a narrow strip of water was saved by only $1 \mathrm{~m}$ on two sides from the fire resulting in the incubator being clearly visible in the charred area.

\section{Distribution of White-naped Cranes within the river basin}

Recordings of nests and of crane observations were significantly associated with river basin sections containing water-bodies $\left(\chi^{2}=19.445, P<0.001\right.$ for nests and $\chi^{2}=$ $7.352, P=0.003$ for crane observations). Recordings of nests or crane observations were not associated with either wetland vegetation type $\left(\chi^{2}=0.825, P=0.662\right.$ for nests and $\chi^{2}=1.148, P=0.563$ for crane observations) or with river basin sections recently burned or unburned $\left(\chi^{2}=2.503, P=0.073\right.$ for nests and $\chi^{2}=0.58, P=0.317$ for crane observations).

\section{Nest-site characteristics and nest-site selection}

All visited nests were originally situated in water-bodies $(n=34,2000$ and 2001). At the time of nest visits (very shallow water-bodies did often dry up or shrink considerably during and after incubation) mean water depth was $<5 \mathrm{~cm}$ at $26 \%$ of nest-sites and $<10 \mathrm{~cm}$ at $70 \%$ of nest-sites $(n=27,2001)$ (Figure 2$)$. More nests $(44 \%)$ showed $<10 \%$ than $>90 \%$ nest concealment $(26 \%)(n=27,2001)$. Most nests were located in wet meadow vegetation $(53 \%)$, in reed or mixed wet meadow/reed vegetation $(29 \%$ and $12 \%$ respectively) $(n=34,2000$ and 2001).

Significantly more nest-sites were in ungrazed areas $(63 \%, n=38)$ than in total home range areas $(24 \%, n=42)\left(\chi^{2}=11.081, P=0.001,2001\right)$. All except one of the ungrazed home range areas were situated in only $c .8 \mathrm{~km}$ length of river basin, the swampy and inaccessible western part of Mongol Daguur Strictly Protected Area.

Nest areas in 2000 in SA I had significantly denser vegetation $\left(\chi^{2}=97.905\right.$, $P<0.001$ ) (Figure 3$)$, were significantly wetter $\left(\chi^{2}=219.797, P<0.001\right)$ and had a significantly lower plant diversity $\left(\chi^{2}=146.298, P<0.001\right)$ than random areas. In contrast to results from 2001, nest areas in 2000 in SA I were dominated by reed areas most likely to remain wet during the drought conditions present in SA I. Random areas were significantly less dominated by reed $\left(\chi^{2}=236.292, P<0.001\right)$ (five nest and six random areas in 2000). 

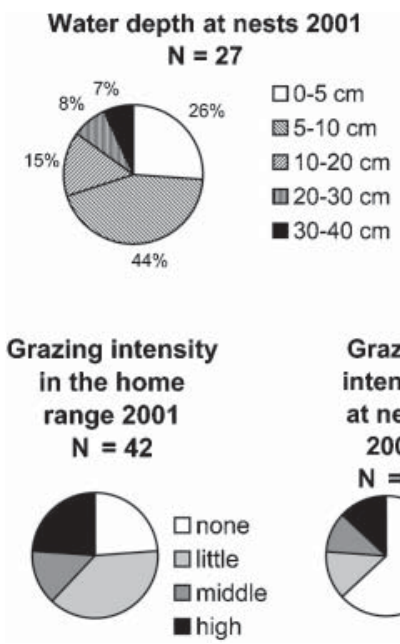
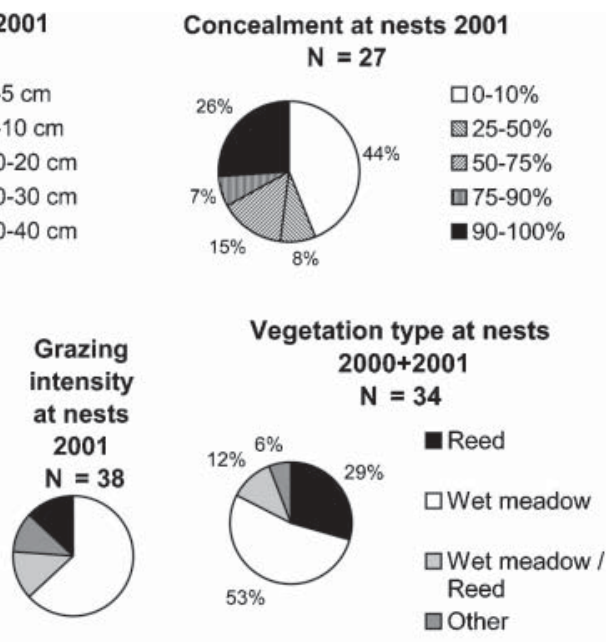

Figure 2. Water depth, concealment, vegetation type, grazing intensity at nests and grazing intensity in the home range of White-naped Crane pairs in north-eastern Mongolia.

Water depth

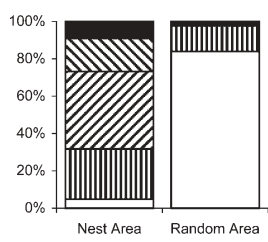

Vegetation type

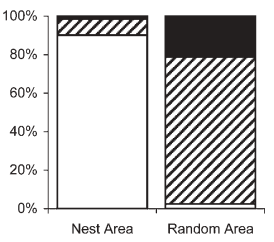

Vegetation density

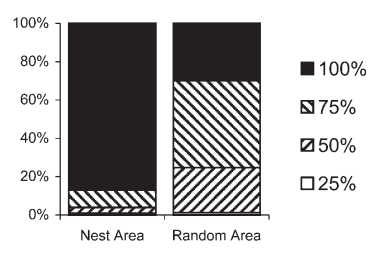

No of plant species

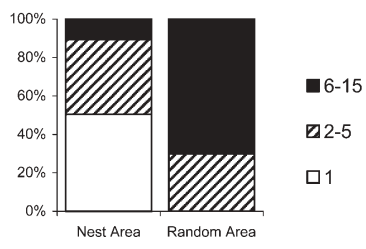

Figure 3. Water depth, vegetation density, vegetation type and number of plant species in five nest areas and six random areas in August 2000 (29 points per nest or random area; $n=145$ and 174, respectively).

Distances to the nearest family home ranged between $500 \mathrm{~m}$ and $4700 \mathrm{~m}(n=6$, 2000).

In 2001, nest-sites had significantly better concealment (Wilcoxon $Z=-3.298$, $P=0.001, n=26$ ) (Figure 4) and significantly lower grazing intensity (sign test, $P=0.016, n=26)$ than random points resembling nest-site features in the same nesting area. Grazing intensity at nest-sites was significantly lower than in the home range (sign test, $P=0.004, n=26$ ). No significant differences were found between water depth and vegetation height at the nest and at random points 

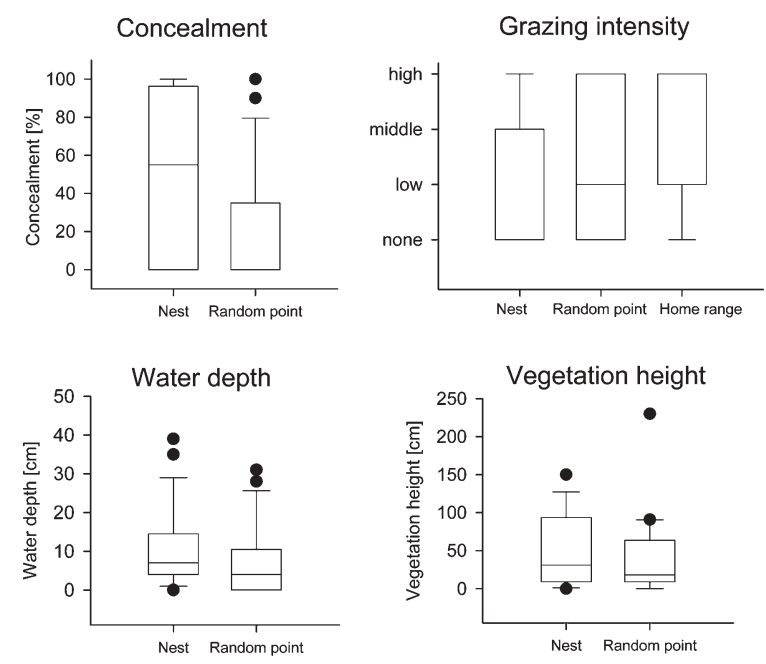

Figure 4. Nest concealment and grazing intensity $(n=26)$, water depth and vegetation height $(n=25)$ at nests and corresponding random points in the same nesting area and grazing intensity in the home range $(n=26)$ of White-naped Cranes in 2001. Box plots show the median, 1oth, 25th, $75^{\text {th }}$ and 90 th percentiles.

(Wilcoxon $Z=-1.572, P=0.116$ for water depth and Wilcoxon $Z=-1.243, P=0.214$ for vegetation height) $(n=25)$.

The percentage of clutches with confirmed hatching increased with water depth at the nest-site, though with a low sample size $(N=24)$ not significantly (Mann-Whitney $U=29.5, P=0.055$ ) (Figure 5). No correlations were found between confirmed hatching and either nest concealment (Mann-Whitney $U=56.0$, $P=0.701$ ), grazing intensity at the nest-site (Mann-Whitney $U=1$ I0.0, $P=0.497$ ) or grazing intensity in the home range (Mann-Whitney $U=134.5, P=0.781$ ). No correlations were found between successful raising of a 4 -week-old chick and either water depth at the nest (Mann-Whitney $U=56.5, P=0.437$ ), nest concealment (Mann-Whitney $U=150.0, P=0.935$ ), grazing intensity at the nest (Mann-Whitney $U=162.0, P=1.0$ ) or grazing intensity in the home range (Mann-Whitney $U=162.5, P=0.799)$.

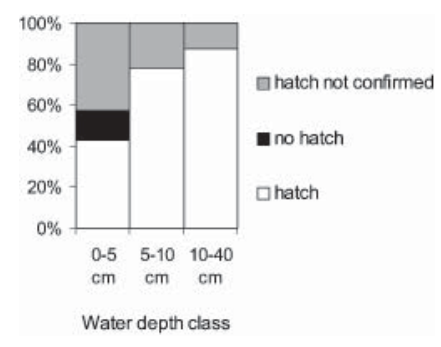

Figure 5. Clutch fate and water depth at 24 White-naped Crane nests in 2001. 'Hatch not confirmed' means that failure cannot be dated to before or after hatch. 


\section{Discussion}

\section{Reproductive performance}

During the study, the number and extent of water-bodies was low compared with other years. During dry periods, the number of White-naped Cranes on the lower Ulz and the Kherlen rivers decreases (Goroshko and Tseveenmyadag 2002). The number of territorial pairs reported in this study, therefore, might not represent average years.

Mean density was 1.5 pairs per $10 \mathrm{~km}$ of river basin length. Highest densities were $4.7-8.8$ pairs per $10 \mathrm{~km}^{2}$. For comparison, Mewes (1996) calculated a density of $0.22-0.7$ breeding pairs per $10 \mathrm{~km}^{2}$ for Eurasian Crane Grus grus in Germany depending on landscape structure. In areas with optimal nest-site availability more than 4 breeding pairs per $10 \mathrm{~km}^{2}$ occur.

The study area is only a part of the Onon-Ulz White-naped Crane breeding range, but still fulfils the current $1 \%$ criterion of 55 birds for the breeding population (Chan 1999) with 84 territorial adult birds (1.53\%). Moreover, in long-lived species such as cranes, the number of breeding birds as a proportion of the total population can be rather low. For example, Alonso and Alonso (1987) estimate $34 \%$ of the non-juvenile population of Eurasian Cranes migrating through Lake Gallocanta, Spain, to be breeding adults. Thus, the breeding birds of our study area might resemble substantially more than $1.53 \%$ of the White-naped Crane breeding population.

Mewes (1999) reports that 18.5\% (8.5-25.1\%, 1985-1998) of European Crane pairs in Germany have not attempted to breed and that in dry territories they do not initiate a clutch. We found that the majority of non-breeding territorial pairs in the Ulz river valley inhabited areas with very shallow, fast-drying water-bodies. A higher proportion of territorial pairs might be breeding in years of average aquatic conditions.

Reproduction rates and population trends are relatively well documented for Whooping Crane Grus americana (e.g. Kuyt 1993, Drewien et al. 1995, Environment Canada 2003a), several populations of Sandhill Crane Grus canadensis (e.g. Safina 1993, Drewien et al. 1995, Littlefield 1995) and Eurasian Crane (Prange and Mewes 1989, Mewes 1996, 1999, Lundgren 1999). Fledging success (45-52\%) and brood-size of breeding pairs (0.6-0.7) in 2001 in this study were lower than the average fledging success $(64 \%)$ and brood-size (0.9) of the increasing German Eurasian Crane population (1978-1998) (Mewes 1999). They were higher or comparable to the average fledging success $(38 \%)$ and brood-size (0.54) of the increasing southwest Swedish Eurasian Crane population (1992-1995) (Lundgren 1999) and the average fledging success $(45 \%)$ of the increasing Wood Buffalo National Park Whooping Crane population (Environment Canada 2003a). Recruitment in this study (18-22\%) was considerably higher than recruitment of the decreasing Malheur National Wildlife Refuge Sandhill Crane population (7\%, 1970-1989) (Littlefield 1995). The data show that reproductive success of the Ulz river population in 2001 was relatively high compared with other crane species, though 2001 was a comparatively dry year. Tseveenmyadag and Goroshko (2001) found $15.7 \%$ juveniles in White-naped Crane flocks in Mongolia in September 2000. Nishida (1981) reported a 16.0\% (4.7-27.8\%) juvenile component in Izumi, Japan in overwintering White-naped Cranes of the eastern population (1968-1972).

We found an increase (though not significant) of confirmed hatching with higher water levels at the nest-site, which probably protect against mammalian predators. 
However, we have no data on water levels and extent of water-bodies in territories and how these influence chick survival. For Whooping Cranes, chick survival is greater in years of above-normal water conditions than in years of below-average water levels (Environment Canada 2003b). Mewes (1999) showed that low annual precipitation negatively influences fledging success in Eurasian Cranes in Germany.

\section{Nest-site selection}

White-naped Cranes have previously been found to prefer wet steppe areas, based on large-scale climate type (Fujita et al. 1994). In this study, the entire study area was located within the wet steppe climate type. On a smaller scale, we found that Whitenaped Crane observations and presence of nests were significantly related to river basin sections containing water-bodies. All visited nests were located in water-bodies. The number and extent of shallow water-bodies are probably a limiting factor for breeding population size. Therefore, the conservation of water-bodies and the water table is of great importance for the long-term survival of the species.

Nest-sites were significantly better concealed than corresponding random points within the nesting area, thus demonstrating that White-naped Cranes prefer nestsites with high nest concealment. However, only $26 \%$ of nests were $>90 \%$ concealed and $44 \%$ of nest-sites had $\leq 10 \%$ nest concealment. This suggests that suitable vegetation for nest concealment was often not available. Overgrazing is a serious problem in Mongolia (Kerr and Treskonova 1995, Oyun-Erdene 1998) and at the end of winter the vegetation in many breeding territories usually becomes very short offering little cover and nest-building material. Ma and Li (1994) report a similar problem from some nature reserves in China where reed-harvesting in winter reduces the availability of suitable nest-sites for White-naped Cranes.

We found no correlation of hatching success or the successful raising of a 4-weekold chick with nest concealment although this was found for Sandhill Cranes in the United States. Littlefield (1995) attributed an improved hatching success to increased nest concealment after substantial reduction in numbers of winter-grazing cattle, with coyotes Canis latrans as the most likely main nest predator. In this study, we rarely found evidence for causes of nest failure, but we assume that the majority of failures are due to predation by avian and mammalian predators. Gombobaatar (2002a) attributes two cases of nest failure of White-naped Cranes in Mongolia to predation by Steppe Eagle Aquila nipalensis, two cases to predation by Eurasian Badger Meles meles and one to predation by Grey Wolf Canis lupus.

A lower grazing intensity at nest-sites than in the home range as found in this study is expected. Some of the nests were located in water-bodies muddy enough to be avoided by livestock although the rest of the territory was grazed. Nest-sites and corresponding random points showed no significant difference in water levels and therefore should not have any significant difference in accessibility to livestock. However, we found a lower grazing intensity at nest-sites compared with corresponding random points, indicating a selection of nest-sites for lower grazing intensity.

We found no correlation of hatching success or successful raising of a 4-week old chick with grazing intensity. But brood-size of successful pairs in ungrazed home ranges was $1.6(n=5)$ whereas in grazed home ranges it was $1.23(n=16)$. On several occasions, adults were seen leaving their nest or becoming separated from their chicks due to disturbance by livestock or horseman. Disturbance by livestock can reduce the time available for parental care and foraging (own observation) and make eggs or 
chicks more susceptible to predation. Therefore, a decrease in brood-size seems a likely consequence. However, the present sample size is small and most ungrazed home ranges in the study area were wetter and muddier than grazed home ranges. Habitat condition itself might have had an impact on brood-size. Possible positive effects of neighbouring human habitation and grazing are discussed by Tseveenmyadag and Goroshko (2001) who mention the possibility of pairs not inhabiting areas without human habitation due to a possibly higher predation risk from, for example, wolves and foxes.

The frequency of steppe fires in north-eastern Mongolia has increased due to anthropogenic reasons. Goroshko and Tseveenmyadag (2002) estimate that in most years $30 \%$ of pairs lose their clutches or chicks or do not attempt to breed due to fires. In this study, no direct losses of eggs or chicks due to steppe fires were recorded. The extent of steppe fires and the time of their occurrence vary greatly between years. Therefore, effects of steppe fires on the White-naped Crane population can be assessed only by long-term studies.

\section{Conclusions}

The study area, part of the main Mongolian Onon-Ulz White-naped Crane breeding area, is of great international importance for the species both because of internationally important numbers of territorial and breeding pairs and because of a potentially high reproductive output. Recruitment reported in this study might have been below average due to drought conditions, but was high in comparison with data on other crane species. Despite the importance of the Mongolian breeding areas for the future of the White-naped Crane, only small areas are presently legally protected.

As shown, water-bodies are of great importance for the long-term survival of the species and activities changing the water table of the river basin would greatly affect the White-naped Crane population. In potential breeding sites, livestock grazing can reduce nest cover and nest-building material and cause disturbance at nests. Therefore, livestock grazing in and adjacent to water-bodies should be avoided during the whole year. Further investigations on the effects of livestock grazing on White-naped Crane reproduction are necessary.

\section{Acknowledgements}

We thank BP Conservation Programme, Stiftung Würth, Stifterverband für die Deutsche Wissenschaft, Southern Helicopters, Jonna Inc., DBA Classics, Mississippi Coast Audubon Society, Mississippi Coast chapter of the Sierra Club, J. \& D. Bird, H. \& J. Briggs, Mr \& Mrs P. B. Cooper, J. Dubuisson, A. Duckett, G. Dunbar, M. Fahnestock, R. H. Goodwin, J. \& G. Grazia, A. Henry, A. \& W. Hornkohl, B. M. Kelly, E. \& I. Methe, G. Morgan, M. Page, M. Peacock, The Perrettis, B. Schaffler, B. \& E. Schaffler, E. Thompson and M. Woodrey for funding. The Protected Area Administration of Eastern Mongolia and the UNDP Eastern Steppe Biodiversity Project in Choibalsan provided advice and logistical support. The weather stations Dashbalbar and Bayan-Uul supplied weather data. B. Oyuntsetseg and Ch. Dulamsuren identified the plant species. S. Davaakhuu and Saranchimeg assisted in the field. We thank Dolgormaa and Bazarbaani, C. Ketzenberg and J. Leyrer, the rangers and our drivers, especially Deriilaa, Chimedseren, Baldshinjam, Chimbat and Lhkagvaa, 
for support and advice in the field and all Ulz river inhabitants offering car parts, tow-ropes and hospitality. F. Bairlein, J. Dierschke, C. Ketzenberg and H. Prange gave valuable comments on an earlier draft of the manuscript.

\section{References}

Alonso, J. A. and Alonso, J. C. (1987) Demographic parameters of the common crane (Grus g. grus) population wintering in Iberia. Aquila 93-94: 137-143.

Bibby, C. J., Burgess, N. D. and Hill, D. A. (1992) Bird census techniques. London. Academic Press.

BirdLife International (200o) Threatened birds of the world. Cambridge, U.K.: BirdLife International.

BirdLife International (2001) Threatened birds of Asia: the BirdLife International Red Data Book. Cambridge, U.K.: BirdLife International.

BirdLife International (2003) Saving Asia's threatened birds: a guide for government and civil society. Cambridge, U.K.: BirdLife International.

Bold, A., Tseveenmyadag, N. and Zvonov, B. M. (1995) Cranes of Mongolia. Pp. 42-47 in C. H. Halvorson, J. T. Harris and S. M. Smirenski, eds. Cranes and storks of the Amur River: The Proceedings of the International Workshop, 3-12 July 1992. Moscow: Arts Literature Publishers.

Chan, S. (1999) Atlas of key sites for cranes in the North East Asian Flyway. Tokyo: Wetlands International Japan.

Drewien, R. C., Brown, W. M. and Kendall, W. L. (1995) Recruitment in Rocky Mountain Greater Sandhill Cranes and comparison with other crane populations. J. Wildl. Manage. 59: $339-356$.

Environment Canada (2003a) About Whooping Cranes. http://www.pnr-rpn.ec.gc.ca/nature/ endspecies/whooping/dbo1so1.en.html. Last updated 25 February 2003.

Environment Canada (2003b) Previous breeding seasons. http://www.pnr-rpn.ec.gc.ca/nature/ endspecies/whooping/dboisi4.en.html. Last reviewed 21 July 2003.

Fisher, I. J. and Swengel, S. R. (1991) A guide for aging Sandhill Crane eggs. Wildl. Soc. Bull. 19: 494-497.

Fujita, G., Harris, J., Bold, A., Tseveenmyadag, N. and Chuluunbaatar, S. (1994) Habitat preference of Demoiselle and White-naped Cranes, Anthropoides virgo and Grus vipio, breeding in Mongolia. Pp. 93-96 in H. Higuchi and J. Minton, eds. The future of cranes and wetlands. Proceedings of the international symposium held in Tokyo and Sapporo, Japan, June 1993. Tokyo: Wild Bird Society of Japan.

Gombobaatar, S. (2002a) Biology-ecological studies of white-naped crane (Grus vipio) in the Onon and Ulz river basins, Mongolia. Pp. 45-47 in D. Pegdel and Z. Enkh-Amgalan, eds. Proceedings of the first conference of young scientists in Mongolia. Ulaanbaatar.

Gombobaatar, S. (2002b) Cranes of the Onon and Ulz river basins. Journal of Mongolian Birds, Amphibians and Reptiles 1: 90-109 (in Mongolian).

Gombobaatar, S. and Sumiya, D. (1998) Protection of cranes in Mongolia. NUM Scientific Journal. Biology No 7: 45-55 (in Mongolian).

Goroshko, O. (2002) The status of crane populations in Transbaikalia and the adjacent territories. Crane Working Group of Eurasia Newsletter 4-5: 38-40.

Goroshko, O. and Tseveenmyadag, N. (2001) White-naped Crane in south-eastern Transbaikalia and north-eastern Mongolia. Pp. 522-529 in E. Kurochkin and I. Rakchimov, eds. Achievements and problems of ornithology of northern Eurasia on a boundary of centuries. Kazan: Magarif Publishers (in Russian with English summary).

Goroshko, O. and Tseveenmyadag, N. (2002) Status and conservation of Cranes in Daurian Steppes (Russia and Mongolia). China Crane News 6: 5-7.

Ilìčev, V. D. and Flint, V. E. (1989) Handbuch der Voegel der Sowjetunion. Volume 4. Galliformes, Gruiformes. Wiesbaden: Aula. 
Kerr, C. and Treskonova, M. (1995) An evaluation of natural grasslands of Mongolia for sustainable management. Lincoln University, New Zealand: Unpublished report.

Kuyt, E. (1993) Whooping crane, Grus americana, home range and breeding range expansion in Wood Buffalo National Park, 1970-1991. Can. Field-Nat. 107: 1-12.

Littlefield, C. D. (1995) Demographics of a declining flock of Greater Sandhill Crane in Oregon. Wilson Bull. 107: 667-674.

Lundgren, S. (1999) Breeding areas, population density and reproduction of Common Cranes (Grus grus) in the Tranemo Area, South Sweden. Pp. 23-25 in H. Prange, ed. Proceedings of the 3rd European Crane Workshop. Halle-Wittenberg.

Ma Yiqing and Li Xiaomin (1994) The population and habitat of cranes in China's nature reserves. Pp. 141-145 in H. Higuchi and J. Minton, eds. The future of cranes and wetlands. Proceedings of the international symposium held in Tokyo and Sapporo, Japan, June 1993. Tokyo: Wild Bird Society of Japan.

Meine, C. D. and Archibald, G. W. (1996) The cranes: status survey and conservation action plan. Gland, Switzerland and Cambridge, U.K.: IUCN.

Mewes, W. (1996) Bestandsentwicklung, Verbreitung und Siedlungsdichte des Kranichs in Deutschland. Vogelwelt 117: 103-109.

Mewes, W. (1999) Zur Reproduktion des Kranichs Grus grus in Deutschland. Vogelwelt 120: 251-259.

Nishida, S. (1981) Wintering life of cranes in Kagoshima and Yamaguchi Prefectures, Japan. Pp. 51-56 in J. C. Lewis and H. Masatomi, eds. Crane research around the world. Proceedings of the International Crane Symposium at Sapporo, Japan and Papers from the World Working Group on Cranes. ICBP.

North East Asian Crane Site Network Newsletter (1998) Volume 1, Number 1. www.wingwbsj.or.jp

Oyun-Erdene, N. (1998) Issues of wetland and pasture management. Pp. 46-58 in Proceedings of International Workshop on Wetland Conservation in Mongolia and North-East Asia: Ulaanbaatar.

Prange, H. and Mewes, W. (1989) Zur Situation des Graukranichs (Grus g. grus) in Mitteleuropa. Beitr. Vogelkd. 35: 240-271.

Safina, C. (1993) Population trends, habitat utilization, and outlook for the future of the sandhill crane in North America: a review and synthesis. Bird Populations 1: 1-27.

Sargent, A. B., Sovada, M. A. and Greenwood, R. J. (1998) Interpreting evidence of duck nests in the prairie pothole region. USGS, Northern Prairie Wildlife Research Center, Jamestown and Ducks Unlimited, Inc. USA.

Sokal, R. R and Rohlf, F. J. (1995) Biometry. Third edition. New York: W. H. Freeman.

Tseveenmyadag, N. and Goroshko, O. (2001) Some results of studies on reproduction and autumn migration of rare cranes in eastern Mongolia. Ecosystem of Eastern Mongolia: 56-63 (in Mongolian).

UTE BRADTER, KLAUS-MICHAEL EXO

Institute of Avian Research, An der Vogelwarte 21, 26386 Wilhelmshaven, Germany

SUNDEV GOMBOBAATAR, CHULUUNBAATAR UUGANBAYAR

National University of Mongolia, Department of Zoology, P. O. Box 537, Ulaanbaatar 210646A, Mongolia

TRACY E. GRAZIA

Mississippi Sandhill Crane National Wildlife Refuge, 7200 Crane Lane, Gautier, MS 39553, U.S.A. 